\title{
A dinâmica multi/transterritorial dos povos Guarani e Kaiowá na fronteira do Brasil com o Paraguai
}

\section{Marcos Mondardo}

\section{Introdução}

Este trabalho tem como objetivo principal investigar a dinâmica multi/transterritorial dos povos Guarani e Kaiowá na fronteira do Brasil com o Paraguai. Nesse processo, identificamos a formação de redes transfronteiriças alternativas e de resistência, especialmente aquelas decorrentes da demarcação das terras indígenas, promovida de maneira mais contundente por grupos envolvidos diretamente na luta pela terra no Mato Grosso do Sul e que vêm se desdobrando na forma de trânsito em direção ao Paraguai.

Para isso, partimos de um debate teórico que prioriza os processos de territorialização por meio da dinâmica multi/transterritorial alternativa, revisitando o conceito de território, associado ao movimento de ir e vir desta fronteira, com ênfase nas territorialidades indígenas local-regionalinternacional. Vinculado a este movimento está à concepção de rede, entendida nesta pesquisa em sua dimensão geográfica, e que interage no interior da área transfronteiriça por meio das territorialidades de luta e resistência por terra, território e direitos humanos.

Nossa pesquisa empírica se desdobrou junto às áreas de intenso conflito entre fazendeiros e Guarani e Kaiowá, em munícipios brasileiros e paraguaios que estão na zona de fronteira. O cone sul do estado de Mato Grosso do Sul é considerado uma das áreas mais férteis para a agricultura moderna, onde se concentra as fazendas de soja, milho, cana-de-açúcar e pecuária, e paradoxalmente onde estão encravados o maior número de reservas e acampamentos indígenas.

Na dinâmica multi/transterritorial produzida pelos povos Guarani e Kaiowá, desenha-se uma complexa superposição e/ou interseção de "fronteiras", áreas e redes configuradas não nas formas tradicionais de interação de fluxos transfronteiriços, mas que envolvem uma trama de relações políticas, econômicas e étnicas na luta pelo reconhecimento e regularização fundiária de seus territórios tradicionais. O papel das múltiplas redes estabelecidas pelos indígenas altera o controle territorial imposto pelos fazendeiros e relativiza os constrangimentos impostos pelos limites internacionais.

\section{A luta pelo reconhecimento dos direitos territoriais em áreas de fronteira}

Vivemos em espaços e tempos do proeminente avanço do capital sobre os direitos territoriais

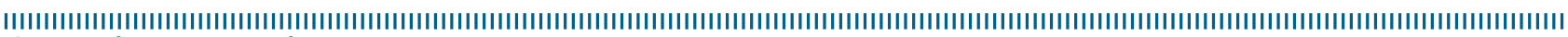
Como citar este artigo:

MONDARDO, Marcos. "A dinâmica multi/transterritorial dos povos Guarani e Kaiowá na fronteira do Brasil com o Paraguai”. In: RÜCKERT, A. A.; SILVA, A. C. P. da; SILVA, G. de V. (Orgs.). Geografia Política, Geopolítica e Gestão do Território: integração sul-americana e regiões periféricas. Porto Alegre: Editora Letra1, 2018, p. 218-233 DOI 10.21507/9788563800367-13 
indígenas no Brasil. Num momento de crise das instituições, a precarização da vida dos povos indígenas, às Propostas de Emenda Constitucional (PECs), às tentativas de mudança do marco temporal face à tradicionalidade da terra definida na Constituição Federal de $1988^{1}$, evidenciam as lutas por redistribuição de terra às lutas pelo reconhecimento de territórios. (FRASER, 2002; 2006).

É no cenário dos ataques recentes sobre o reconhecimento dos direitos territoriais indígenas que analisamos a questão das territorialidades de insegurança dos povos Guarani e Kaiowá na área de fronteira do Brasil com o Paraguai, no sul do Mato Grosso do Sul. No conflito com fazendeiros ${ }^{2}$, os Guarani e Kaiowá constroem estratégias biopolíticas (AGAMBEN, 2002) de territorialização alternativa (HAESBAERT, 2007) em acampamentos às margens de importantes rodovias de fluxos do agronegócio, a exemplo da BR 163 que perpassa o estado de norte a sul. Com isso, os povos indígenas criaram dispositivos territoriais de luta pela terra e direitos humanos, em especial com o fechamento temporário de rodovias e o trânsito multi/transterritorial pela fronteira. (MONDARDO, 2012; 2014; 2017).

Partimos do pressuposto que esse ir e vir por múltiplos territórios fronteiriços dos povos Guarani e Kaiowá, além de ser uma prática cotidiana devido aos laços de parentesco, aos casamentos, as relações interétnicas, tornou-se uma estratégia geopolítica fundamental na luta pelos direitos

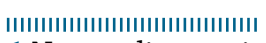

1 No que diz respeito à questão indígena, a Constituição Federal de 1988, em seu capítulo VIII, artigo 231, reconhece que os índios têm direito de acesso à terra ao determinar que todas às Terras Indígenas do país devem ser identificadas, delimitadas, demarcadas e homologadas pela União. A lei determina que: "São reconhecidos aos índios sua organização social, costumes, línguas, crenças e tradições, e os direitos originários sobre as terras que tradicionalmente ocupam, competindo à União demarcá-las, proteger e fazer respeitar todos os seus bens". (CONSTITUIÇÃO FEDERAL, 1988, art. 231, [grifos nossos]).

2 Os fazendeiros analisados neste trabalho são aqueles que personificam de maneira mais radical esta "condição moderna" do agronegócio, latifundiários em sua maioria, e que assumem posições radicalmente contrárias ao processo de demarcação das terras indígenas. Na maioria, são migrantes e filhos de migrantes, oriundos da região Sul do Brasil e chamados de "gaúchos". (MONDARDO, 2009a, 2009b; 2012). territoriais na medida em que permite construir “espaços equivalentes” (MA MUNG, 1999) dos dois lados da fronteira internacional, possibilitando, por exemplo, obter vantagens econômicas, políticas e até mesmo culturais.

O conflito entre fazendeiros e indígenas (Guarani e Kaiowá) em Mato Grosso do Sul ganhou dimensões em múltiplas escalas, principalmente, nas últimas duas décadas com as medidas relativas às demarcações das terras tradicionais. No Mato Grosso do Sul a resistência política e territorial que se iniciou de forma organizada na década de 1970, deu um passo fundamental em 2007 para a agenda de luta pelo reconhecimento dos direitos territoriais destas populações tradicionais, com a publicação das portarias da Fundação Nacional do Índio (FUNAI) em acordo com o Ministério Público Federal (MPF), que determinaram o início do processo de demarcação das terras indígenas.

Esse ato jurídico-político, no entanto, foi o estopim para o acirramento do conflito territorial que já vinha ocorrendo historicamente entre indígenas e fazendeiros nesta região, e que se acentuou com a possibilidade de uma reconfiguração fundiária no cone sul do estado, que compreende a área de fronteira do Brasil e Paraguai. Com isso, o conflito pelo reconhecimento de territórios ganhou novas dimensões políticas e escalas de luta, com alianças e coalizões dos dois lados envolvidos na questão, por meio de redes de relações de poder ampliadas em suas bases locais de enfrentamento. (MONDARDO, 2014).

No início do ano de 2013, a mídia nacional e até internacional mostrou ao mundo o caso da Terra Indígena Buriti, no Mato Grosso do Sul, lugar de conflito agudo. ${ }^{3}$ Este episódio de tensão (mais um dentre outros que se multiplicam pelo estado) demonstrou, dentre outras possíveis reflexões, o "Estado de exceção" (AGAMBEN, 2004) que

IIIIIIIIIIIIIIIIIIIIIIIIIIIIIIIIIIII

3 Em maio de 2013 os indígenas reocuparam a terra indígena Buriti, com cerca de 300 hectares, e reivindicaram a posse plena da terra reconhecida como território tradicional. Entretanto, no movimento de reintegração de posse foi morto o indígena terena Oziel Gabriel. Para maiores informações, ver, por exemplo, matéria veiculada pela FUNAI, disponível em: <http://www.funai.gov.br/ index.php/comunicacao/noticias/528-pericia-inicia-trabalhos-deapuracao-da-morte-do-indigena-oziel-gabriel>. 
vivem os povos indígenas hoje, pois o próprio Estado tornou-se, neste exemplo, um mantenedor de certa "ordem de segurança", mesmo que para isso assumindo uma posição, em certo sentido, de "terrorista", ou em outras palavras, por colocar em prática uma tanatopolítica. (AGAMBEN, 2002).

Como contraponto a este racismo de Estado (FOUCAULT, 2005; BERNARDES, 2013), uma das formas de descolonização do imaginário geográfico hegemônico se deu pela pelas estratégias políticas, práticas e discursos colocados em curso que reconstruíram as territorialidades dos povos indígenas em luta. Se, por um lado, fazendeiros (muitos destes, "gaúchos") buscam sua legitimidade pela manutenção da propriedade da terra (a chamada "segurança jurídica”), de outro, os Guarani e Kaiowá lutam pelo reconhecimento de seus territórios tradicionalmente ocupados em busca de "justiça social".

Se, de um lado, no estado existem algumas das fazendas mais ricas do país, do outro, Guarani e Kaiowá, em condição dramática de precariedade, vivem em territórios de contenção (reservas indígenas), em situações de conflitos político-identitários que demonstram a situação de vulnerabilidade socioeconômica que foram submetidos. Do processo de tensão e conflito entre fazendeiros e indígenas produziram-se novas e alter-nativas territorialidades de resistência na lutam contra o preconceito, exploração, ocultamento e invisibilidade para a valorização e afirmação simbólica-cultural da identidade territorial dos Guarani e Kaiowá. No município de Dourados, onde residem aproximadamente $20 \%$ da população indígena do estado, organizam-se em ações coletivas, seja pelo fechamento temporário de rodovias, ocupações de áreas com estudos de demarcações e/ou praticam-se trânsitos pela fronteira internacional entre acampamentos e reservas, com o objetivo de fortalecer a luta para o retorno aos tekoha. ${ }^{4}$

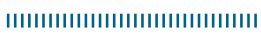

4 Segundo Pereira (2009), tekoha é formada pela junção das palavras em guarani Teko + Há. Assim, Teko significa o modo de vida, e Há, à espacialidade dessa vivência. Sendo assim, as frases utilizadas "sem tekoha não há teko" ou "sem teko não há tekoha” demonstram a relação indissociável entre a base material
Num estado controlado socioterritorialmente pelo agronegócio, as lavouras de soja, de canade-açúcar e as pastagens dominam a paisagem ao se estenderem por milhares de quilômetros quadrados. Essa realidade produziu diferentes e divergentes processos de territorialização, em estratégias, ações e discursos coletivos variados contra os povos Guarani e Kaiowá. Se, de um lado, os fazendeiros (em sua maioria, "gaúchos") construíram seus impérios pela lógica destruidora da "modernização da agricultura", de outro, esse processo promoveu a expropriação/ desterritorialização, pela implementação da biopolítica colonial de "contenção territorial", de milhares de povos indígenas em reservas.

Esse conflito nos levou a analisar como a "constituição da sociedade moderno-colonial" (MIGNOLO, 2003; 2005; QUIJANO, 2015), nessa região de fronteira do Brasil com o Paraguai foi se expandindo e impondo formas de dominação e apropriação da terra, da divisão territorial do trabalho, das hierarquizações sociais, da invisibilidade e ocultamento do Outro (indígena, neste caso) e da multiplicidade de níveis de relações sociais entre sujeitos distintos que se revelou, territorialmente, em múltiplos processos de desterritorialização. Por isso, é importante compreender de que modo na fronteira do Brasil com o Paraguai as classes sociais e as etnias são construídas e negociadas nas situações de conflito fundiário e de reconhecimento de territórios tradicionais.

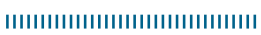

e simbólica (indispensável para qualquer grupo humano) e a cultura, o modo de vida dos Guarani e Kaiowá, da mesma forma que sem a cultura não pode existir tekoha. Como analisamos em Mondardo (2012), hoje o tekoha é o espaço de referência simbólica e política de reconstrução das identidades territoriais dos Guarani e Kaiowá em Mato Grosso do Sul que estão em luta pela demarcação e regularização de suas terras tradicionais. Por isso, o tekoha assume uma dimensão geográfica pela ênfase dada à terra como fator indispensável ao "seu modo de ser" e que nas condições atuais de reserva ou acampamento é limitante e precário; uma dimensão histórica pelas ligações da comunidade de natureza temporal com a espacialidade e construída pela identificação, afetividade e religiosidade; e, podemos acrescentar, hoje, uma terceira, a dimensão política, que se refere ao caráter de resistência pela atualização de lutas históricas para o reconhecimento dos direitos territoriais como a terra e o território, além da melhoria nas condições precárias de saúde, educação, moradia, dentre outros. 
Para estudar os desiguais meios de luta entre fazendeiros e indígenas, analisamos a "geometria de poder" (MASSEY, 2000) do conflito territorial, com enfoque para as articulações e políticas transescalares das territorialidades diretamente envolvidas. Trazemos ao debate, assim, às diferentes estratégias de luta pela terra, território e direitos humanos, no sentido de revelar os sujeitos sociais que ajudam no "empoderamento" ou no enfraquecimento dos grupos.

Analisamos, com isso, a construção de um território-rede pela articulação de sujeitos sociais à distância, com desigual uso e apropriação do "meio técnico-científico-informacional" (SANTOS, 1997), em escalas de ações que partem do local e se articulam em nível regional, nacional e até internacional, num jogo de forças, de divergência, de interesses, que põem, frente a frente, fazendeiros e Guarani e Kaiowá. Nesse "salto" complexo de escalas (SWYNGEDOUW, 2010), de sobrepor e articular espaços desenhamse multiterritorialidades em ambos os lados envolvidos na questão como uma possibilidade concreta e também virtual de acessar lugares estratégicos na luta pelos territórios tradicionais, de um lado, e dos "direitos de propriedade", de outro. Se os fazendeiros buscam a chamada “segurança jurídica" de suas propriedades, os povos indígenas lutam e resistem em busca de "justiça social".

Essas multi/transterritorialidades (HAESBAERT \& MONDARDO, 2010) produzidas pela/na fronteira articulam, como veremos, múltiplos territórios num jogo multiescalar construído por redes econômicas, políticas e culturais entre Brasil e Paraguai. Do lado dos fazendeiros "gaúchos", verificamos que essa territorialidade é produzida por redes funcionaleconômicas vinculadas ao "mundo" do agronegócio para a dominação de espaços agrícolas, as fazendas. Por parte dos Guarani e Kaiowá uma territorialidade subalterna de trânsito é produzida ao articular acampamentos e reservas, no Mato Grosso do Sul, no lado brasileiro, com terras indígenas, no lado paraguaio, que funciona no "empoderamento" da luta por território e direitos humanos.

\section{Multi/transterritorialidades em áreas de fronteira}

Nas últimas duas décadas têm crescido os estudos em áreas ou contextos de fronteira internacional, urbanas e nos limites étnico-raciais entre os mais variados grupos ou sujeitos sociais. Por isso, consideramos que a fronteira ganhou uma dupla conotação no âmbito das lutas dos movimentos sociais na América Latina, assumindo uma centralidade analítica e outra política, ou seja, tornou-se "categoria de análise" e "categoria da práxis". O conceito de fronteira tem sido um caminho epistêmico em vários campos disciplinares das Ciências Sociais e tem se constituído como uma categoria fundamental para pensar as lutas de diferentes grupos sociais. Já a fronteira como evidência empírica, tornou-se uma "categoria da práxis" na medida em que tem funcionado como um dispositivo de agenciamento discursivo e prático/estratégico de grupos e/ou movimentos sociais que lutam pelo reconhecimento das suas diferenças territorial-identitárias.

Em Mato Grosso do Sul a produção de territórios, de certo modo, deve ser pensada na relação com a fronteira. Os processos contemporâneos de reconhecimento de uma condição transterritorial e transfronteiriça, associada aos direitos territoriais, estão presentes nas reivindicações dos Guarani e Kaiowá presentes no espaço sul-mato-grossense. A vivência e o trânsito por diferentes "territórios" e "culturas" nos permitem, assim, pensar a possibilidade da produção de multi/transterritorialidades na luta dos povos indígenas pela demarcação de suas terras tradicionais, e nas atividades do agronegócio desenvolvidas pelos fazendeiros "gaúchos" que tem propriedades em ambos os lados da fronteira entre Brasil e Paraguai. Por isso, é necessário discutirmos, especialmente no âmbito da Geografia, o que vem a ser multiterritorialidade e a transterritorialidade, ou o que estamos chamando de multi/transterritorialidade.

A noção de "multiterritorialidade" desenvolvida por Haesbaert (2001; 2002; 2004; 2005; 2007), foi proposta para demonstrar a forma 
dominante contemporânea e/ou "pós-moderna" da reterritorialização, e para "contrapor" ao que muitos equivocadamente acredita(va)m acontecer hoje, ou seja, a desterritorialização em favor de uma menor relação/incorporação/ referência dos sujeitos e/ou grupos com o espaço. A desterritorialização "é consequência direta da predominância, especialmente no âmbito do chamado capitalismo pós-fordista ou de acumulação flexível", "das relações sociais construídas através de territórios-rede, sobrepostos e descontínuos, e não mais através de territórios-zona, que marcam aquilo que podemos denominar modernidade clássica territorial-estatal" (2004, p. 338). Isso não implica no desaparecimento, em hipótese alguma, de formas "antigas" de território que ainda continuam presentes, complexificando e formando novas organizações espaciais.

Conforme Haesbaert (2004), vivemos, no mundo contemporâneo, muito mais do que o domínio da desterritorialização, a construção de "territórios múltiplos" e a possibilidade de vivenciar uma "multiterritorialidade". Se, para o autor, "territórios múltiplos" seriam as distintas lógicas de territorialização que convivem lado a lado, a multiterritorialidade se manifesta por uma "reterritorialização complexa em rede" "resultante não apenas da sobreposição ou da imbricação entre múltiplos tipos territoriais (o que inclui territórios-zona e territórios-rede)", mas a "experimentação/reconstrução de forma singular pelo indivíduo, grupo social ou instituição" da sua multiterritorialidade (p. 343).

A multiterritorialidade, a partir das proposições de Haesbaert (2004), se manifesta de duas formas geográficas: uma, de caráter mais amplo, que pode ser denominada de "multiterritorialidade lato sensu" ou sucessiva, e envolve a vinculação de múltiplos territórios (zonais) articulados em rede, implicando, para os grupos sociais um determinado grau de mobilidade física; e outra, de caráter mais específico, que denomina "multiterritorialidade stricto sensu" ou simultânea, e que envolve territórios em si mesmos híbridos e/ou que permitem a articulação simultânea com outros territórios, por exemplo, por mecanismos de controle informacional.
A multiterritorialidade envolve uma alternância não simplesmente quantitativa - pela abertura ampliada de alguns sujeitos para acessar, conectarse a diversos territórios - mas, sobretudo, qualitativa, tendo em vista que a possibilidade de entrar, sair e combinar a vivência de vários tipos de territórios, reconstruindo, assim, uma territorialidade de multipertencimento e sobreposição territorial. A condição para a efetiva realização da multiterritorialidade é a presença de uma multiplicidade de territórios e territorialidades, bem como sua articulação na forma, principalmente, de territórios-rede. Esses territórios são sempre múltiplos e conjugam maneiras de controle nas mais variadas escalas e sobreposições territoriais, seja nas formas de territórios-zona ou em redes de conexão, desenham uma "multiterritorialização".

Propomos, de acordo com o Haesbaert e Mondardo (2010), que é por demonstrar o trânsito e a trans-formação, sempre abertos e em movimento simultâneo (embora desigual) dos diferentes sujeitos envolvidos no processo de transculturação, que o prefixo trans pode evidenciar os processos de hidridização/ (trans)territorialização. Da mesma forma que hidridização não diz respeito a uma condição estática, a transterritorialidade não corresponde a uma situação estável, mas a um processo sempre aberto e incessante desse ir e vir, ser/não-ser, ou, mais propriamente, de um devir entre territórios/ territorialidades que potencializa essa passagem, de entrada e saída, de trocas/alternâncias de territórios, que se configura nas vivências e pelos trânsitos por distintos territórios. Assim:

Enquanto a multiterritorialidade pode implicar a passagem de um território (ou territorialidade) para outro, assumindo-se novas condições em momentos diferentes de um mesmo processo ainda que temporalmente próximos entre si -, a transterritorialidade é a manifestação de uma multiterritorialidade em que a ênfase se dá no estar-entre, no efetivamente híbrido, produzido através dessas distintas territorialidades. (...) Transterritorialidade, assim, envolve não apenas o trânsito ou a passagem de um território ou territorialidade a outra mas a transformação efetiva 
dessa alternância em uma situação nova, muito mais híbrida. Destaca-se a própria transição, não no sentido de algo temporário, efêmero e/ou de menor relevância, mas no sentido de "trânsito", movimento e do próprio "atravessamento" e imbricação territorial - não um simples passar-por mas um estar-entre. (HAESBAERT E MONDARDO, 2010, p. 15-16).

O que importa "é a condição de possibilidade, sempre em aberto, de nossa inserção em 'território alheio' (que também passa, assim, de forma ambivalente, a ser 'nosso')", pois é “a abertura desses territórios que coloca permanentemente a possibilidade de entrar, sair e/ou transitar por essas territorialidades". (HAESBAERT E MONDARDO, 2010, p. 14).

Como considera Haesbaert (2011a, p. 7), "pelo 'transitar' efetivo por múltiplos territórios, posso afirmar que estamos produzindo uma multiterritorialidade - ou, num termo mais adequado, uma transterritorialidade”. Essa implica "mais do que a articulação de territórios diferentes, o trânsito entre eles, a sua imbricação pela frequente mobilidade". O autor alerta que a aliança entre hibridismo e transterritorialidade "só se dá de fato quando uma mudança de território/territorialidade implica efetivamente numa mudança de comportamento e numa mescla cultural".

Mais do que dissociados, devemos lembrar que a transterritorialidade se manifesta por meio da multiterritorialidade. Por isso, em áreas de fronteiras entre países a possibilidade de acessar múltiplos territórios à escala internacional, constantemente redesenhados pelas relações sociais, permite acessar a vivência e os trânsitos por territórios/territorialidades que se interpenetram e se cruzam. Esses ire-vires transfronteiriços podem revelar uma espacialidade mais complexa, marcadas pelos limites sociais e pelo trânsito de territorialidades nacionais, étnicas, de classe, dentre outras. Em nosso caso focalizamos as relações que envolvem o conflito territorial dos Guarani e Kaiowá e fazendeiros "gaúchos" na fronteira do Brasil com o Paraguai.

\section{Territorialidades de insegurança na luta pela demarcação das terras indígenas}

Segundo o Censo do IBGE (2012), em 2010 a população indígena do Brasil era de 896.900 pessoas e a região Centro-Oeste tinha o terceiro maior contingente, contando com 130.494 índios, dos quais 34.238 vivem na área urbana e 96.256 na zona rural. Já o espaço sul-mato-grossense contava nesse mesmo ano com a segunda maior população indígena do país (atrás apenas do estado do Amazonas com 168.680), sendo estimada em 73.295 pessoas e, destes, 41.500 são Guarani e Kaiowá. Na participação relativa da população nacional (dos 190.732.694 habitantes) os Guarani e Kaiowá representam 0,02\% e na estadual (dos 2.449 .024 residentes) $1,69 \% .^{5}$

O conflito territorial, no entanto, só passou a ganhar espaço e destaque na mídia nacional e até internacional na última década por causa dos números alarmantes de genocídios, suicídios, homicídios e atropelamentos no Mato Grosso do Sul. O relatório de Violência Contra os Povos Indígenas do Brasil produzido pelo Conselho Indigenista Missionário - CIMI (2011), aponta que no período de 2003 a 2010, a situação de precariedade/instabilidade territorial dos Guarani e Kaiowá pode ser observada nos 250 homicídios, 176 ocorrências de suicídios (principalmente, entre os mais jovens), 190 tentativas de homicídios e das 4.000 crianças que sofreram desnutrição.

A mesma pesquisa revela que só no ano de 2003 a taxa de mortalidade infantil por desnutrição atingiu o registro de 93 crianças para cada 1000 nascimentos (é o índice mais alto de

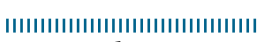

5 Segundo a FUNASA (2012), os dados do Sistema de Informação de Atenção à Saúde Indígena (SIASI) apresentam em 2010 "um total de 600.518 indígenas cadastrados, distribuídos em 4.774 aldeias dentro ou fora dos limites de 615 terras indígenas, correspondendo a 448 municípios em 24 estados brasileiros. (...) nas regiões Norte e Centro-Oeste do país reside $64 \%$ da população indígena, em $98 \%$ das terras indígenas. Em contrapartida, nas demais regiões localizam-se apenas $2 \%$ das terras indígenas legalizadas e em processo de legalização, com $36 \%$ da população indígena do país. Em 2010, a distribuição da população indígena pelas regiões brasileiras foi: $46,2 \%$ da população indígena na região Norte, $25,4 \%$ no Nordeste, $17,7 \%$ no Centro-Oeste e $10,7 \%$ nas regiões Sul-Sudeste". 
mortalidade infantil em populações indígenas do Brasil). Também conta com mais da metade dos assassinatos entre indígenas em todo o país: no ano de 2008 foram 42 dos 60 ocorridos e, em 2009, 33 dos 60 registrados. Em 2010, das 1.015 lesões corporais sofridas pelos povos indígenas no Brasil, 1.004 aconteceram no estado, e das 152 ameaças de morte, 150 ocorreram no Mato Grosso do Sul.

Outro relatório elaborado pelo CIMI (2013), com dados do ano de 2012, aponta que a maioria das formas de violência cometidas contra os povos indígenas, quando comparado com os casos de 2011, aumentou em 2012. Um crescimento de $237 \%$ foi constatado somente neste ano na categoria "violência contra a pessoa", que envolve ameaças de morte, homicídios, tentativas de assassinato, racismo, lesões corporais e violência sexual. A categoria "vítimas de violência" teve um aumento de $76 \%$. Ainda, segundo esta pesquisa, foram cometidos 60 homicídios contra indígenas no Brasil em 2012, o que representa nove mortes a mais do que no ano anterior. O maior número ocorreu em Mato Grosso do Sul, que contabilizou 37 casos, seguido de Maranhão e Bahia, com sete e quatro casos, respectivamente. Nos últimos dez anos ocorreram 563 assassinatos de indígenas em todo o país.

A seguir, na figura 1, verificamos a situação da violência contra indígenas no Brasil com dados de 2014. Neste ano, de acordo com Relatório do CIMI (2014), o Mato Grosso do Sul apresentou uma situação alarmante de violência. Foram 27 assassinatos, 12 tentativas de assassinatos, 9 homicídios culposos, 7 ameaças de morte, 6 casos de violência sexual, 5 lesões corporais dolosas e 3 ameaças de outra natureza, que totalizam 67 ocorrências no estado.

Dados mais recentes apontam para a continuidade dos conflitos relativos aos direitos territoriais no Brasil, com destaque para o Mato Grosso do Sul. Segundo o CIMI (2016), foram

Figura 1. Violência contra indígenas no Brasil - 2014.

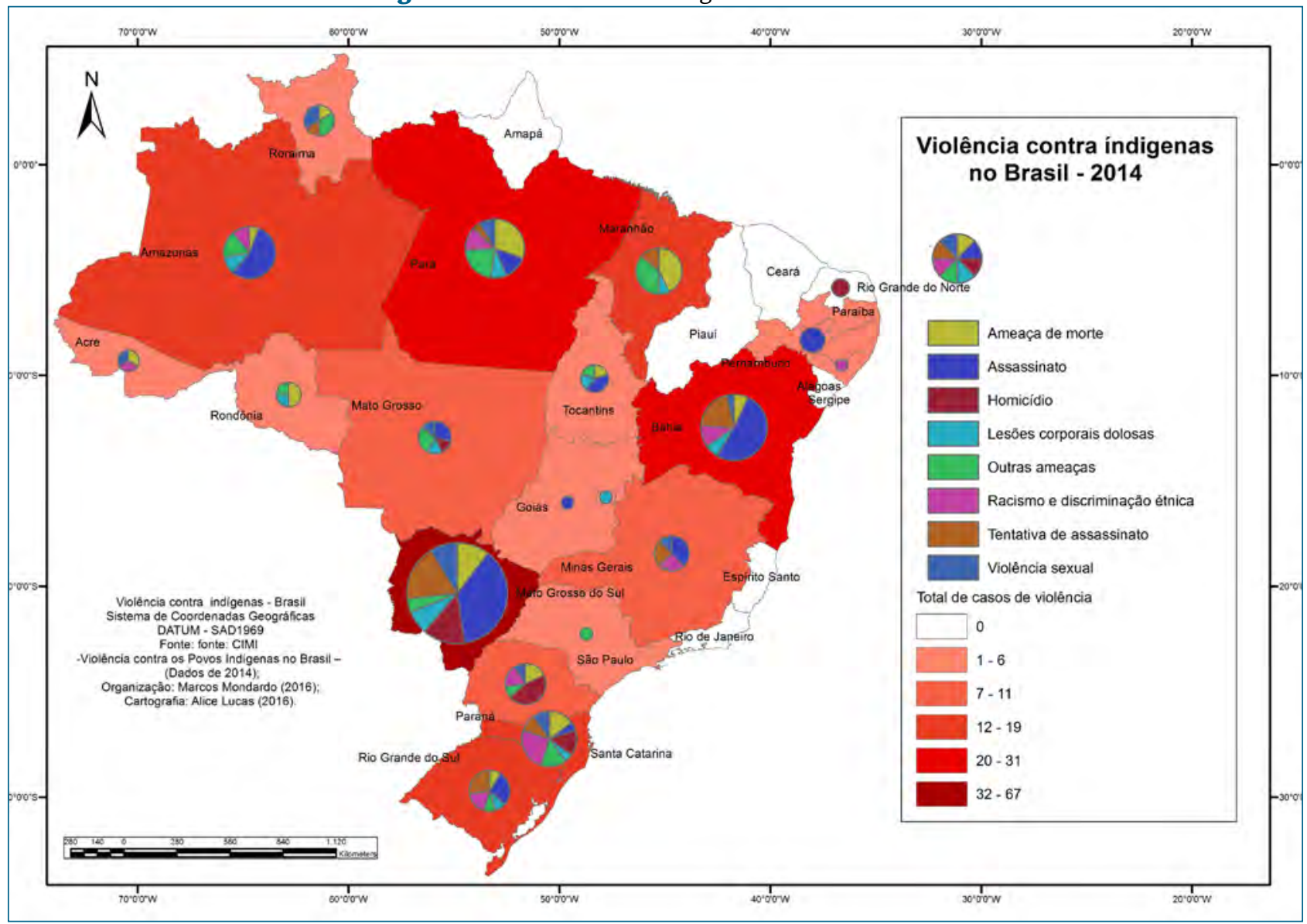


registrados no ano de 2016, 12 ocorrências de conflitos relativos à luta por territórios tradicionais, uma nos estados de Amazonas, Mato Grosso, Pernambuco, Santa Catarina e Rio Grande do Sul, e sete no Mato Grosso do Sul. Com isso, um dos destaques do relatório de 2016 foi a situação dos Guarani e Kaiowá no Mato Grosso do Sul, o qual continua apresentando o maior número de casos de violência contra indígenas no país. A média geral de homicídios no estado é de $27,71 \%$ de pessoas a cada 100 mil habitantes, mas entre os povos indígenas é de $43,26 \%$, e entre os Guarani e Kaiowá a média sobe para os impressionantes $62,26 \%$. Os recentes ataques ocorreram nas comunidades indígenas das terras Kurusu Ambá, Dourados Amambaipeguá e Guaiviry.

A omissão do poder público, a morosidade nos processos de regularização fundiária (a diminuição acentuada do ritmo das demarcações de Terras Indígenas no Brasil), a contenção territorial de populações numerosas em pequenas reservas apinhadas de índios e a situação de precariedade estão entre as violações mais praticadas contra as populações tradicionais. Utilizando dados da FUNAI (2016), calculamos que a Reserva indígena de Dourados apresenta a densidade demográfica de 86,7 habitantes $/ \mathrm{km}^{2}$, a Reserva Indígena de Amambai é de 207,7 índios por $\mathrm{km}^{2}$, e nas Reservas indígenas do município de Antônio João é de aproximadamente 10 habitantes $/ \mathrm{km}^{2}$. Vale ressaltar que estas densidades demográficas são maiores que as dos municípios (e do estado) onde estão localizadas estas reservas. Além disso, segundo dados do CIMI, existem no Brasil, 1296 pedidos de demarcações de territórios tradicionais, mas apenas $30 \%$ estão sendo analisados.

Isso nos leva a afirmar que o desrespeito aos direitos indígenas faz parte de uma política de insegurança adotada pelo Estado. A tanatopolítica e o "racismo de Estado" estão no cerne destas violações. Essa situação demonstra uma condição de vivência para estas populações tradicionais em Estado de exceção permanente. O direito a viver está condicionado à subdivisão da população, pelo "racismo de Estado", em segmentos diferenciados pelo chamado "nível de civilização". Assim, algumas vidas passam a ser consideradas "indignas de serem vividas" (AGAMBEN, 2004, p.146), num jogo ambivalente que permite, dependendo da relação de forças, o fazer viver ou o fazer morrer, por exemplo, as populações indígenas:

Essa articulação não assegura o direito à vida das populações indígenas, ela apenas serve como ferramenta para investir ou não nas formas de viver. Mesmo em se tratando de incentivos à vida, isso não salvaguardará as populações indígenas do deixar morrer, na medida em que as formas de vida "civilizatórias" também apresentavam mecanismos de aniquilação da vida, como é observado nos aldeamentos, que colocavam as populações indígenas em uma condição de confinamento. É justamente esse jogo que anuncia o estado de exceção. (BERNARDES, 2011, p. 161).

O Estado pode investir e fazer viver certos segmentos da população indígena quando lhe interessar, ou fazer morrer quando estas vidas não estiverem na esteira dos interesses da Nação. No entanto, não podemos esquecer que os direitos conquistados pelas minorias estão relacionados à capacidade de organização e mobilização na forma de movimentos.

Outro fator que contribui para a violência sofrida pelos povos Guarani e Kaiowá é a política neodesenvolvimentista do governo do estado de Mato Grosso do Sul que enxerga os indígenas, pelo ângulo econômico, como "barreira" ao "progresso", pelo "mundo do agronegócio". Muitas vezes a violência contra as comunidades tradicionais tem partido de quem deveria protegê-las: o Estado. Nesse sentido, a condição de "Estado de exceção" em que vivem estas populações torna-se alarmante, pois o próprio Estado tornou-se difusor do "terrorismo". Sobre esta condição de um terrorismo de Estado, Agamben afirma que:

Hoje enfrentamos os mais extremos e perigosos desenvolvimentos no pensamento da segurança. Ao longo de uma gradual neutralização da política e a progressiva capitulação das tarefas tradicionais do Estado, a segurança se tornou o princípio básico da atividade do Estado. Um Estado que tem a segurança como sua única tarefa e origem de legitimidade é um 
organismo frágil; ele sempre pode ser provocado pelo terrorismo para se tornar, ele próprio, terrorista. (AGAMBEN, 2002, p. 22).

O espaço sul-mato-grossense, campo da territorialização do agronegócio, encontra-se, hoje, numa situação de exceção, já que desde o seu ordenamento institucional-territorial, até as suas práticas políticas, inclusive de "segurança", tornaram as medidas de exceção uma regra, o que leva a uma crise do Estado Democrático. Isso evidencia que as medidas de "emergência" tomadas pelo Estado para mediar o conflito territorial ou na tentativa de apaziguar a tensão, tornou-se uma regra, haja vista os inúmeros processos jurídicos e políticos que se arrastam no cenário moroso e espinhoso da demarcação das terras indígenas. ${ }^{6}$

Nesse sentido, Célia Collet explica que as Terras Indígenas são definidas da seguinte maneira (COLLET, 2014, p. 79-80):

- Terras em estudo: quando são feitos estudos antropológicos, históricos, fundiários, cartográficos e ambientais que fundamentam a delimitação de uma terra indígena.

- Terras delimitadas: são as terras que tiveram a conclusão dos estudos publicados no Diário Oficial da União pela FUNAI e se encontram em análise pelo Ministério da Justiça, para eventual expedição de Portaria Declaratória da Posse Tradicional Indígena.

- Terras declaradas: são terras que obtiveram a expedição da Portaria Declaratória e tem demarcações autorizadas;

- Terras homologadas: são aquelas que foram demarcadas e tiveram seus limites homologados pela Presidência da República;

- Terras regularizadas: se referem às que, após a homologação de seus limites, foram registradas em cartório em nome da União e no Serviço de Patrimônio da União;

||I|||||||||||||||||||||||||||||||||

6 Segundo o Portal Uol Notícias (15/07/2009), em março de 2009 "No Tribunal Regional Federal da 3 ${ }^{\text {a }}$ Região, [haviam] 87 processos envolvendo conflitos entre fazendeiros e índios, cujo problema central é a disputa de terras".
- Reservas indígenas: correspondem às terras doadas por terceiros, adquiridas ou desapropriadas pela União, que não se confundem com as de posse tradicional e, por esse motivo, não se submetem aos procedimentos anteriormente descritos.

De acordo com a FUNAI (2016), no Brasil existiam 462 terras regularizadas que representam $12,2 \%$ do território nacional. Por região, as Terras Indígenas regularizadas estão distribuídas da seguinte maneira: $54 \%$ estão no Norte; $19 \%$ no Centro-Oeste; 11 \% no Nordeste; $10 \%$ no Sul; $6 \%$ no Sudeste. ${ }^{7}$

A maior parte delas está concentrada na Amazônia Legal e esse fato é explicado pela política de integração nacional e consolidação das fronteiras norte e noroeste na década de 1980. Nas demais regiões do país, os povos indígenas foram mantidos em áreas reduzidas e esparsas, muitas delas reconhecidas pelo Serviço de Proteção ao Índio (SPI) entre os anos de 1910 e 1967, sem levar em conta os requisitos necessários para reprodução biológica e cultural dos povos indígenas. ${ }^{8}$

De acordo com os dados da FUNAI de 2016, no estado de Mato Grosso do Sul 29 terras indígenas estão regularizadas, 5 homologadas, 10 declaradas, 4 delimitadas e 15 em estudo. Essa situação territorial permite afirmar que os grupos étnicos deste estado residem em 29 Terras Indígenas, enquanto 34 Terras estão em fases de processos de regularização fundiária.

A seguir, na figura 2, apresentamos, com base nesses dados, a situação das Terras Indígenas nas fases terras em estudo, regularizadas, delimitadas e declaradas.

Com base nos dados do Instituto Socioambiental (2013), podemos afirmar que as áreas reivindicadas pelas populações indígenas no Brasil somam quase dois milhões de hectares e incluem terras

||I|||||||||||||||||||||||||||||||||||

7 “Terras indígenas, o que é?". (FUNAI). Disponível em: <http://www.funai.gov.br/index.php/2014-02-07-13-2432?limitstart=0\#> Acesso em: 05/11/2016.

8 “Terras indígenas, o que é?”. (FUNAI). Disponível em: <http://www.funai.gov.br/index.php/2014-02-07-13-2432?limitstart=0\#> Acesso em: 05/11/2016. 
Figura 2. Situação das terras indígenas no Mato Grosso do Sul.

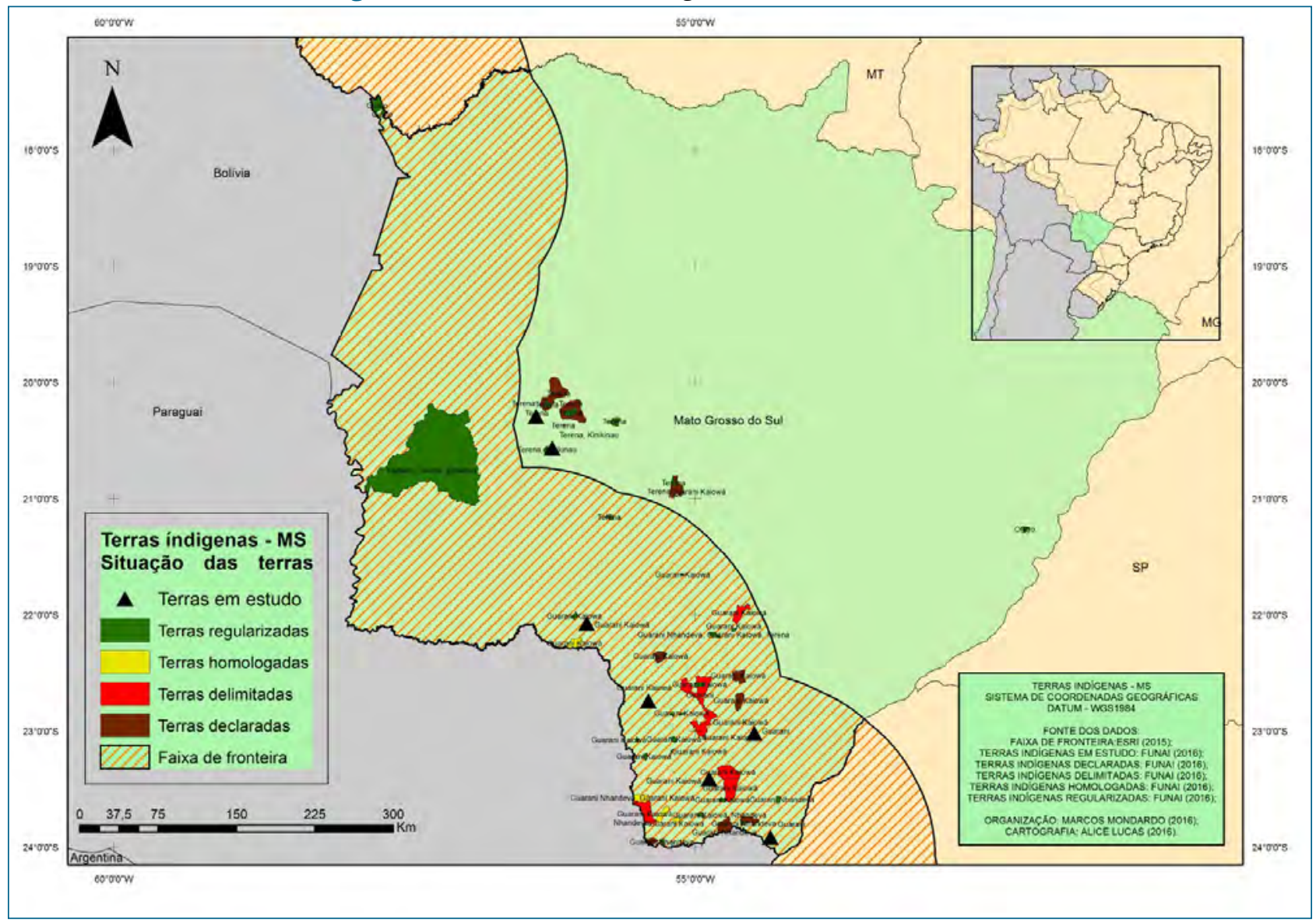

em vários estados como em Mato Grosso do Sul, Rio Grande do Sul e Santa Catarina.

No entanto, devido à insuficiência de terras para uma população numerosa, o estado de Mato Grosso do Sul apresenta demandas urgentes. Mesmo em situação de "territorialização de exceção", vivem no Mato Grosso do Sul cerca de 77.000 índios ou $8,5 \%$ da população indígena do território nacional, segundo maior contingente do Brasil. (MONDARDO, 2013). As Terras Indígenas no espaço sul-mato-grossense somam apenas $0,7 \%$ da área total se comparadas às terras indígenas

|||||||||||||||||||||||||||||||||||||

9 Para Mondardo (2013, p. 16), "o indígena está numa condição de ‘territorialização de exceção' porque permanece num limbo entre o ordenamento territorial estatal criado para ele (a reserva indígena), e a condição de "desterritorializado" pela precariedade em que vive sem as condições mínimas de reprodução físico-biológica. $\mathrm{O}$ Estado, com isso, "nega" ou suspende seus direitos socioterritoriais e assume postura de "terrorismo" com medidas emergenciais que, assim, se tornam a regra da política contemporânea para esses povos". brasileiras. Essa situação, embora com alguma diferença em relação aos dados apresentados com base na FUNAI, demonstra o reduzido número de Terras Indígenas no estado como podemos observar na figura 3.

Esses mapas (figuras 2 e 3 ) evidenciam uma geografia indígena presente no Brasil e invisibilizada pelos projetos hegemônicos de modernização do território nacional. Os processos de reconhecimento dos territórios tradicionais demonstram, hoje, a necessidade de aprofundarmos a análise espacial destes novos/ velhos limites territoriais. É fundamental, assim, destrincharmos as formas e os conteúdos em que a fronteira assume no espaço sul-mato-grossense, em suas múltiplas dimensões e escalas, para desdobrarmos seu potencial analítico e no front (práxis) destes povos tradicionais. 
Figura 3. Situação das terras indígenas no Brasil.

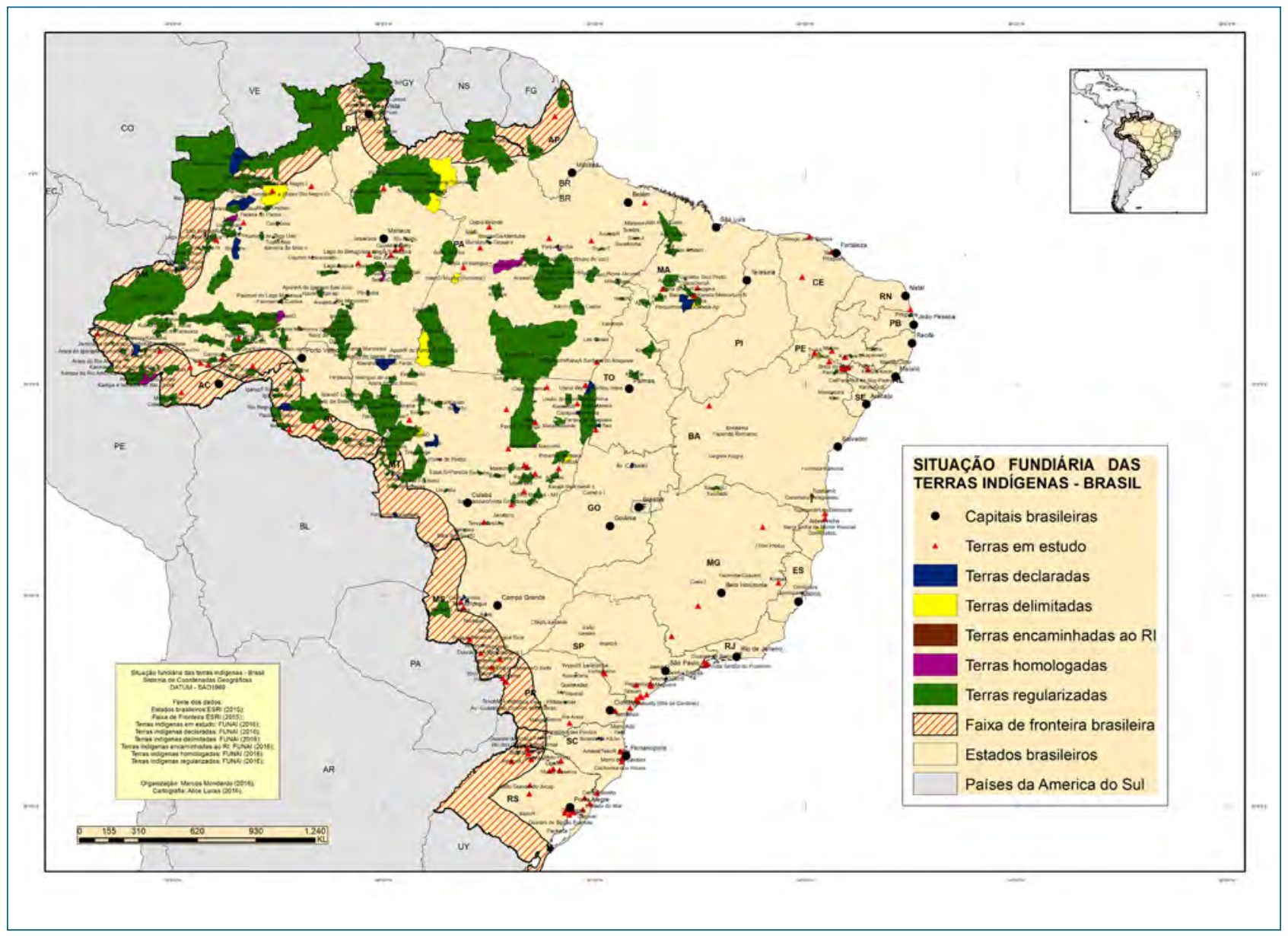

\section{Multi/transterritorialidades dos} povos Guarani e Kaiowá na fronteira

A construção de multi/transterritorialidades dos Guarani e Kaiowá na luta por territórios tradicionais diz respeito ao trânsito e a vivência entre múltiplos "territórios" políticos de ação coletiva, o que possibilita a construção de "espaços equivalentes" (MA MUNG, 1999) nos dois lados do limite internacional entre Brasil e Paraguai. A vivência concomitante, ou sucessiva, em inúmeras escalas, do trânsito e vivência entre vários "territórios" como nas reservas, nos acampamentos, e nas relações construídas com entidades/organizações articula, como analisamos, uma rede de luta e empoderamento.

Essa multi/transterritorialidade também está em elaboração por meio dos fenômenos associados à "geometria de poder da compreensão tempo- espaço", retomando a discussão de Massey (2008). Os novos meios de comunicação/ informação interferem diretamente na vida, na organização social e na construção dos territórios e territorialidades dos Guarani e Kaiowá. O telefone celular, por exemplo, exerce importância para as visitas familiares, na organização de festas religiosas, na luta pela terra, no contato com órgãos do Estado como o Ministério Público Federal (MPF), CIMI, ONGs, com políticos, pesquisadores, dentre outras conexões/articulações que ajudam e permitem a troca de informações em escalas mais amplas de interação.

O celular possibilita em certa medida para estes sujeitos se conectarem sem deslocamento físico com outros territórios, redesenhando multi/ transterritorialidades simultâneas que permitem a articulação pelas maiores ligaç̃oes e vínculos que são construídos, agora, também, à distância 
com comunidades indígenas transfronteiriças, a exemplo das localizadas no Paraguai. Cabe ressaltar que é relativamente comum na fronteira o uso de telefones celulares com números de ambos os países (Brasil e Paraguai) para as comunicações. Isso permite ganhos econômicos e até locacionais nas trocas de informações.

Do mesmo modo que os novos meios de comunicação/informação proporcionaram uma "compressão das relações espaço-temporais" (HARVEY, 1994) na sociedade branca-ocidental, os Guarani e Kaiowá, em níveis desiguais de apropriação/incorporação, usam aparelhos de celular, TV, computador, internet, câmeras de vídeo, dentre outros equipamentos, para dar visibilidade às suas lutas. Esses se tornaram meios de comunicação e de transmissão de saber entre as lideranças com a comunidade externa, além das redes de articulação com as entidades/ organizações e movimentos sociais.

Para atuarem no fortalecimento dessas redes políticas e culturais entre índios da Reserva de Dourados, por exemplo, as lideranças (em grande medida) tecem uma rede de comunicação e transmissão de saber com os acampamentos às margens de rodovias ou em fundos de terras, com os acampamentos de retomadas de território em áreas "reocupadas" de fazenda. Cabe mencionar as ligações com entidades mais diretamente envolvidas na questão indígena como o CIMI, MPF, FUNAI, FUNASA, com políticos e representantes de movimentos sociais.

Hoje, se torna até relativamente comum circular pela internet e-mails de indígenas de todo o Brasil denunciando situações de conflito, de violência, de genocídio, ou até mesmo anunciando "suicídio coletivo". Replicam-se campanhas em escala nacional e até internacional sobre a necessidade de retorno desses povos originários para seus tekoha. Esses novos meios de comunicação transformaram as noções de espaço e de tempo da comunidade Guarani e Kaiowá. Ao mesmo tempo em que permitem maior velocidade de deslocamento de informações (do próprio "saber tradicional") com interferência direta na direção e nos itinerários construídos em suas territorialidades, possibilitam e potencializam as articulações com outros "territórios".

Além disso, os povos indígenas constroem redes por meio de suas territorialidades alternativas e de resistência, que envolvem a vinculação de múltiplos territórios (zonais) articulados. Essa articulação em múltiplas redes implica, para os Guarani e Kaiowá, um grau de mobilidade física em ambos os lados da fronteira internacional como podemos ver no quadro 1.

Quadro 1. Redes transfronteiriças dos povos guarani e kaiowá.

Tipos de redes Características

São construídas pela articulação de acampamentos, terras e reservas indígenas do lado brasileiro e do lado paraguaio. As relações que envolvem os territórios nacionais são sobrepostas com aquelas que dizem respeito às relações interétnicas entre indígenas de tekoha distintos, da circulação de informações, de organização e mobilização política em torno da Aty Guassu (ou grande reunião), até para o refúgio em situações de conflito agudo. Ao mesmo tempo em que a fronteira é um espaço de insegurança para as territorialidades indígenas, pela perseguição a certas lideranças Guarani e Kaiowá, ela se torna um abrigo para aqueles que buscam se refugiar, de um ou de outro dos limites nacionais, a depender da situação de tensão em que suas vidas estão em jogo.

São aquelas que permitem trocas materiais e simbólicas entre grupos indígenas de ambos os lados da fronteira. Os Guarani e Kaiowá que residem no Brasil e até no Paraguai podem obter alguns benefícios assistenciais (nem sempre) garantidos pelo Estado brasileiro dos Programas de transferência de renda do Ministério de Desenvolvimento Social e Combate à Fome (MDS), como a distribuição de Cestas Básicas, o Benefício de Prestação Continuada (BPC) previsto na Lei Orgânica de Assistência Social (LOAS), bem como assistência médico-hospitalar e educação.* Nas cidades de Ponta Porã e Coronel Sapucaia (Brasil), por exemplo, crianças Guarani moram nas cidades paraguaias de Pedro Juan Caballero e Capitán Bado e estudam em escolas brasileiras.

Redes econômicas Essas políticas, mesmo que malogradas, constroem uma diferença entre as terras e reservas indígenas do lado brasileiro e do lado paraguaio nesta fronteira. Alguns Guarani e Kaiowá afirmam que, devido estes benefícios assistenciais, reservas e terras indígenas brasileiras são "melhores" do que às paraguaias. No espaço sul-mato-grossense constatamos que essas políticas atendem situações críticas e outras ações emergenciais tendo em vista a pobreza e a precariedade a que foram submetidos estes povos.** Além disso, observamos pequenas ajudas financeiras, trocas de alimentos e roupas e até alguns objetos eletrônicos (como celulares), entre indígenas que residem no Mato Grosso do Sul, Brasil, com parentes que residem em terras localizadas nos Departamentos de Amambay e Canindeyú, no Paraguai. Nessa rede transfronteiriça identificamos que a melhoria das rodovias e das linhas de ônibus, além de estradas vicinais, ajudaram na maior mobilidade física dos Guarani e Kaiowá na contemporaneidade. 
Quadro 1. Cont.

São construídas por uma espécie de "circularidade matrimonial" ou o trânsito transfronteiriço dos povos Guarani e Kaiowá, principalmente, por meio de casamentos entre membros de tekoha distintos localizados em ambos os lados da fronteira internacional. Esse translado é construído por laços étnicos e consanguíneos que dão unidade e mantém esse fluxo transfronteiriço. O ir e vir é utilizado, inclusive, como "trunfo espacial" pelos "espaços equivalentes" gerados que potencializam a luta pela demarcação das terras indígenas no Mato Grosso do Sul.
\end{abstract}

\begin{abstract}
*. Para Quermes e Carvalho (2013, p. 782), utilizando dados da Secretaria Nacional de Assistência Social do Ministério de Desenvolvimento Social (SNAS/MDS), "em Dourados, estão cadastrados 4.516 beneficiários do BPC (Benefício de Prestação Continuada) e 188 de RMV (Renda Mensal Vitalícia), totalizando 4.702 benefícios de transferência direta condicionada. São 4.491 na área urbana e 104 na zona rural da população não indígena e 90 de população moradora em reserva indígena. Outros 17 benefícios não foi informada a localização. Do total, 2.243 são benefícios do sexo masculino e 2.452 do sexo feminino. Quanto à natureza do benefício do BPC, 2.724 são BPC Idosos, destinado aos maiores de 65 anos, 1.790 referemse aos beneficiários do BPC PCD (Pessoas Com Deficiência), destinado as pessoas com deficiência. No caso da população indígena, a totalidade dos benefícios de BPC enquadrase na categoria de BPC PCD. Considerando apenas os indígenas com deficiência beneficiários do BPC, foram identificados 88 benefícios e duas de RMV Invalidez, totalizando 90 benefícios. Desse total, 41 são benefícios do sexo feminino e 49 do sexo masculino, sendo que as aldeias de Bororó e de Jaguapiru, nos quais se encontram índios da etnia Guarani Kaiowá, sozinhas concentram 71 benefícios".

**. Yazbek (2008) destaca dados do Plano Brasil Sem Miséria ao revelar "que dos 817.963 indígenas no país, 326.375 se encontram na extrema pobreza, representando cerca de $40 \%$ desse contingente populacional".
\end{abstract}

Elaboração: Marcos Mondardo, 2017.

Nesse ir e vir eles se deslocam fisicamente e podem passar alguns meses no Paraguai e outros no Brasil. Por isso, para estes povos a fronteira é um espaço de trânsito transfronteiriço e permite que os Guarani e Kaiowá acionem os "territórios" do mesmo grupo étnico ao cruzar a fronteira, num sentido de passagem e de "contornamento" (HAESBAERT, 2011c), convivendo com os seus semelhantes dos dois lados e, de certo modo, ignorando ou mesmo relativizando os limites da fronteira nacional.

\section{Considerações finais}

Ao demonstramos o contexto espaçotemporal em que se insere a luta pelo reconhecimento dos territórios tradicionais dos Guarani e Kaiowá, percorremos os meandros das territorialidades de insegurança destes povos. A fronteira do Brasil com o Paraguai demonstra esta maleabilidade transfronteiriça - o espaço de trânsito - que o redesenhar de limites por muito tempo tem feito desta um território de múltiplas redes.

A dinâmica multi/transterritorial nesta fronteira indica constantes mobilizações sociais e políticas entre povos indígenas e fazendeiros. Não existe somente multiterritorialidades "lado a lado", de oposição ou antagonismo entre indígenas e fazendeiros, mas, também, com algum nível de relações de convivência (embora esta última não tenha sido analisada neste trabalho). As redes transfronteiriças de relações geográficas podem nos dar uma noção de como existe uma dinâmica de territorialidades indígenas que transgride os limites dos territórios nacionais, brasileiro e paraguaio, e se projeta, pela multiplicidade de relações e de lugares, e parece ignorar e/ ou relativizar muitas vezes os imperativos da fronteira internacional.

É importante considerar que as territorialidades Guarani e Kaiowá não são elaboradas por concepções de limites/fronteiras e de identidade permeadas por estabilidades/ exclusivismos dos territórios nacionais, dos padrões moderno-ocidentais, vinculados à lógica territorial tradicional, embora, como demonstramos, se apropriam e interagem com tais. Devido a essa complexa geograficidade indígena redesenhada nesta região de fronteira do Brasil com o Paraguai, convivem outras lógicas espaciais distintas, porém em certo nível combinadas, às lógicas zonal e reticular.

Os povos Guarani e Kaiowá fazem uso do padrão zonal de organização dos territórios nacionais (brasileiro e paraguaio), de caráter contínuo, e combinam as suas relações com redes 
transfronteiriças, de padrão descontínuo. Por isso, as multi/transterritorialidades analisadas não excluem estas lógicas espaciais. Apresentamos exemplos evidentes nas redes destacadas. $\mathrm{O}$ indígena Guarani e Kaiowá em seu trânsito pela fronteira vivencia a ambiguidade de duas lógicas de organização espacial: ao mesmo em que parece se encaixar no controle (nem sempre) rígido fronteiriço internacional, constrói por meio de múltiplas redes políticas, econômicas e étnicas, relações de solidariedade, de ajuda, de trocas comerciais, informacionais, afetivas e políticas, o que qualifica o caráter transfronteiriço de sua territorialidade. Com isso, subverte a lógica imposta à sua territorialidade de insegurança para ganhar benefícios e articular "espaços equivalentes" transfronteiriços. Sendo a fronteira um espaço de trânsito para estes povos, as territorialidades dos Guarani e Kaiowá assumem feições múltiplas, intercâmbios em rede e na luta pelo reconhecimento de seus tekoha.

\section{Referências}

AGAMBEN, G. Estado de exceção. São Paulo: Boitempo, 2004. AGAMBEN, G. Homo Sacer: o poder soberano e a vida nua I. Belo Horizonte: EdUFMG, 2002.

A TENSÃO INDÍGENA com a gestão Temer. Disponível em <https://brasil.elpais.com/brasil/2016/05/21/ politica/1463864670_330401.html $>$.

BERNARDES, A. G. Saúde indígena e políticas públicas: alteridade e estado de exceção. Interface - Comunicação, Saúde, Educação, v.15, n.36, p.153-64, jan./mar. 2011.

BERNARDES, C. R. O. Racismo de Estado: uma reflexão a partir da crítica da razão governamental de Michel Foucault. Curitiba: Juruá, 2013.

BRASIL. Constituição (1988). Constituição da República Federativa do Brasil. Brasília, DF: Senado Federal: Centro Gráfico, 1988. 292p.

CASTRO, E. V. de. No Brasil todo mundo é índio, exceto quem não é. In: SZTUTMAN, E. (ORG.). Eduardo Viveiros de Castro. Rio de Janeiro: Beco do Azougue, 2008.

Centro de Trabalho Indigenista Situação dos Detentos Indígenas do Estado de Mato Grosso do Sul. Brasília: CTI, 2008. 60p.

COLLET, Célia, et. All. Quebrando preconceitos: subsídios para o ensino das culturas e histórias dos povos indígenas. Rio de Janeiro: Contra Capa Livraria; LACED, 2014.

CONSELHO INDIGENISTA MISSIONÁRIO - CIMI. As violências contra os povos indígenas em Mato Grosso do Sul: e as resistências do bem viver por uma terra sem males (dados 2003-2010). Mato Grosso do Sul: CIMI, 2011.
CONSELHO INDIGENISTA MISSIONÁRIO - CIMI. Violência contra os Povos Indígenas no Brasil - Dados de 2012. Brasília: CIMI, 2013.

CONSELHO INDIGENISTA MISSIONÁRIO - CIMI. Violência contra os Povos Indígenas no Brasil - Dados de 2014. Brasília: CIMI, 2014.

CONSELHO INDIGENISTA MISSIONÁRIO - CIMI. Violência contra os Povos Indígenas no Brasil - Dados de 2016. Brasília: CIMI, 2016.

FOUCAULT, M. Ditos e escritos volume IV: estratégia, podersaber. 3a. ed. Rio de Janeiro: Forense Universitária, 2012.

FOUCAULT, M. Em defesa da sociedade: curso no Collége de France (1975-1976). 2. ed. São Paulo: Martins Fontes, 2005

FOUCAULT, M. Naissance de la Biopolitique. Paris: GallimardSeuil, 2004.

FOUCHER, M. Fronts et frontières: un tour du monde géopolitique. 3 ed. Paris: Fayard, 2004.

FOUCHER, M. L'invention des frontières. Paris: Fondation pour les Études de Defense Nationale, 1986.

FOUCHER, M. Obsessão por fronteiras. São Paulo: Radical Livros, 2009.

FRASER, N. A justiça social na globalização: redistribuição, reconhecimento e participação. Revista Crítica de Ciências Sociais, 63: 7-20, 2002.

FRASER, N. Redistribución ou reconocimiento? In: FRASER, N. \& HONNETH, A. Redistribución ou Reconocimiento? Madrid: Ediciones Morata, 2006.

FUNAI dados de 2016. Disponível em <http://www.funai. gov.br/index.php/indios-no-brasil/terras-indigenas $>$. Acesso em 05/11/2016.

FUNASA/MS. População indígena. Disponível em: <http:// sis.funasa.gov.br/transparencia_publica/siasiweb/ Layout/quantitativo_de_pessoas_2010.asp>. Acesso em 20/06/2012.

HAESBAERT, Rogério. Região e redes transfronteiriças em áreas de migração brasileira nos vizinhos do Mercosul. In: STROHAECKER, T. M. et al. (Orgs.). Fronteiras e Espaço Global. Porto Alegre, AGB, 1998, pp. 59-68.

HAESBAERT, R. Le mythe de la déterritorialisation. Géographies et Cultures. n. 40. Paris: L'Harmattan, 2001.

HAESBAERT, R. Sociedades biopolíticas de in-segurança e des-controle dos território. In: OLIVEIRA, M. et al. (Org.). O Brasil, a América Latina e o mundo: espacialidades contemporâneas. Rio de Janeiro: Lamparina, Faperj e ANPEGE. 2008.

HAESBAERT, R. A multiterritorialidade do mundo e o exemplo da Al Qaeda. Terra Livre. n. 7. São Paulo: Associação dos Geógrafos Brasileiros, 2002.

HAESBAERT, R. O mito da desterritorialização: do "fim dos territórios" à multiterritorialidade. Rio de Janeiro: Bertrand Brasil, 2004.

HAESBAERT, R. Da Desterritorialização à Multiterritorialidade. Anais do X Encontro de Geógrafos da América Latina. São Paulo: Universidade de São Paulo, 2005, p. 6774- 6792. 
HAESBAERT, R. Território e Multiterritorialidade: um debate. GEOgraphia, Niterói: UFF, v. 9, n. 17, p. 19-45, 2007.

HAESBAERT, R. Dilema de conceitos: espaço-território e contenção territorial. In: SAQUET, M. A. SPOSITO, E. S. Territórios e territorialidades: teorias, processos e conflitos. São Paulo: Expressão Popular, 2009, p. 95-120.

HAESBAERT, R. Viviendo en el límite: los dilemas del hibridismo y de la multi/transterritorialidad. In: Zusmán, P. et al. (Org.) Geografias Culturales: aproximaciones, intersecciones y desafios. Fac. De Filosofía y Letras da UBA. Buenos Aires, 2011a.

HAESBAERT, R. O território e a nova des-territorialização do Estado. In: DIAS, L. C. FERRARI, M. (Orgs.). Territorialidades humanas e redes sociais. Florianópolis: Insular, 2011b.

HAESBAERT, R. Da multiterritorialidade aos novos muros: paradoxos da des-territorialização contemporânea. In: JESUS, Eduardo de (Orgs.). Artes e novas espacialidades: relações contemporâneas. Rio de Janeiro: F10, 2011c.

HAESBAERT, R. Multi/transterritorialidade e "contornamento": do trânsito por múltiplos territórios ao contorno dos limites fronteiriços. In: FRAGA, Nilson Cesar. (Org.). Territórios e fronteiras: (re)arranjos e perspectivas. Florianópolis: Insular, 2011d.

HAESBAERT, R.; MONDARDO, M. Transterritorialidade e antropofagia: territorialidades de trânsito numa perspectiva brasileiro-latino-americana. GEOgraphia, n. 24, 2010.

HARVEY, D. Condição pós-moderna: uma pesquisa sobre as origens da mudança cultural. São Paulo: Edições Loyola, 1994.

IBGE. Os indígenas no Censo Demográfico 2010: primeiras considerações com base no quesito cor ou raça. Ministério do Planejamento, Orçamento e Gestão. Rio de Janeiro, 2012.

INSTITUTO Socioambiental (2013). Governo mantém na gaveta 21 processos de demarcação de Terras Indígenas. Disponível em <http://www.socioambiental.org/pt-br/ node/2356> Acesso em 01/09/2013.

LATIFUNDIÁRIOS BRASILEIROS acusados de tráfico têm fazendas no Paraguai. Disponível em <https://deolhonosruralistas.com.br/ deolhonoparaguai/2017/11/17/latifundiarios-acusadosde-trafico-de-drogas-brasileiros-tem-fazendas-noparaguai/>. Acesso em 2/11/2017.

MA MUNG, E. Autonomie, Migration et alterité. Dossier pour l'obtention de l'habilitation à diriger des recherches. Poitiers: Université de Poitiers, 1999.

MASSEY, D. Um sentido global de lugar. In: ARANTES, A. A. (Org.). O espaço da diferença. SP: Papirus, 2000, pp. 176-185.

MASSEY, D. Pelo espaço: uma nova política da espacialidade. Rio de Janeiro: Bertrand Brasil, 2008.
MIGNOLO, W. Histórias locais/projetos globais: colonialidade, saberes subalternos e pensamento liminar. Belo Horizonte: UFMG, 2003.

MIGNOLO, W. Habitar la frontera: sentir y pensar la descolonialidad. Barcelona, Ediciones Bellatera, 2005.

MONDARDO, M. Os períodos das migrações: territórios e identidades em Francisco Beltrão/PR. Dissertação (Mestrado em Geografia), Faculdade de Ciências Humanas, Universidade Federal da Grande Dourados. Dourados/MS, 2009a.

MONDARDO, M. Mobilidade sulista do capital e da força de trabalho para o Mato Grosso do Sul: modernização agroindustrial, descompassos e contradições sócioterritoriais. Terra Livre, v. 1, p. 173-187, 2009b.

MONDARDO, M. Conflitos territoriais entre GuaranisKaiowás, paraguaios e "gaúchos": a produção de novas territorialidades no Mato Grosso do Sul. (Tese de Doutorado em Geografia). Programa de Pós-Graduação em Geografia da Universidade Federal Fluminense: Niterói, 2012.

MONDARDO, M. No território do agronegócio à luta pelo retorno ao tekoha: o conflito territorial envolvendo Guarani-Kaiowá e fazendeiros em Mato Grosso do Sul. Revista GeoNorte, v. 7, 2013, p. 767-781.

MONDARDO, M. A geometria de poder do conflito territorial entre fazendeiros e Guarani-Kaiowá na fronteira do Brasil com o Paraguai. Acta Geográfica (UFRR), 2014, p. 185-202.

MONDARDO, M. Territorialidades de insegurança e estratégias biopolíticas dos povos Guarani e Kaiowá na fronteira do Brasil com o Paraguai. L'Espace Politique, 31, 2017-1. Consultado em 27 novembro 2017. Disponível em <http://espacepolitique.revues.org/4212>. DOI: 10.4000/espacepolitique.4212

PEREIRA, J. Os Terena de Buriti: formas de organização, territorialização e representação da identidade étnica. Dourados: UFGD, 2009.

QUERMES, P. A. de A.; CARVALHO, J. A. de. Os impactos dos benefícios assistenciais para os povos indígenas: estudo de caso em Aldeias Guaranis. Serv. Soc. Soc., São Paulo, n. 116, p. 769-791, out./dez. 2013.

QUIJANO, A. Colonialidade do poder, eurocentrismo e América Latina. In: LANDER, E. (Org.). A colonialidade do saber: eurocentrismo e ciências sociais. Perspectivas latinoamericanas. Buenos Aires: CLACSO, 2005, pp. 107-130.

RESERVAS INDÍGENAS do Mato Grosso do Sul estão entre as regiões mais violentas do mundo. Disponível em: <https://racismoambiental.net.br/2016/10/28/ reservas-indigenas-do-mato-grosso-do-sul-estao-entreas-regioes-mais-violentas-do-mundo/>. Acesso em 18/05/2017.

SANTOS, M. Técnica, espaço, tempo: globalização e meio técnico-científico-informacional. 3 ed. Hucitec: São Paulo, 1997. 
SWYNGEDOUW, E. Gobalización o glocalización? redes, territórios e reescalamiento. In: FERNÁNDEZ, V. R.; BRANDÃO, C. Escalas y políticas del desarrolho regional: desafios para América Latina. Buenos Aires, Miño Dávila, 2010.
YAZBEK, M. C. Estado e políticas sociais. Revista de Estudos de Política e Teoria Social. Rio de Janeiro. Universidade Federal do Rio de Janeiro, v. 18, n. 1, 2008.

\section{Marcos Mondardo}

Doutor em Geografia pela Universidade Federal Fluminense. É professor do Programa de Pós-Graduação em Geografia na Universidade Federal da Grande Dourados. Tem experiência na área de Geografia Humana, com ênfase em Geografia Regional, Geografia Política e Geografia Cultural, atuando no ensino e na pesquisa com os seguintes conceitos e/ou temas: território, territorialidade, região e fronteira.

E-mail: marcosmondardo@yahoo.com.br 